\title{
УПРАВЛЕНИЕ ЧЕЛОВЕЧЕСКИМИ РЕСУРСАМИ
}

УДК: 005.95/.96

JEL: J240

\section{HR-БОТЫ В УПРАВЛЕНИИ ЧЕЛОВЕЧЕСКИМИ РЕСУРСАМИ ОРГАНИЗАЦИИ}

\section{B. Н. Минина}

Санкт-Петербургский государственный университет, Российская Федерация, 199034, Санкт-Петербург, Университетская наб., 7-9

Для цитирования: Минина В. Н. 2019. НR-боты в управлении человеческими ресурсами организации. Вестник Санкт-Петербургского университета. Менеджмент 18 (3): 400-418. http://doi.org/10.21638/11701/spbu08.2019.304

Статья посвящена анализу относительно нового явления цифровой экономики возникновению HR-ботов. На основе анализа литературы определено понятие «HR-бот». Выделены виды HR-ботов, сферы их применения и функции в процессе управления человеческими ресурсами, оценены возможности в повышении эффективности HR-функции организации, рассмотрены вызовы, с которыми сталкиваются HR-подразделения при внедрении в практику управления HR-ботов. В то же время подчеркивается, что HRботы - это инструменты, предназначенные для повышения производительности труда и качества работы HR-специалистов, и вряд ли оправдано ожидание того, что они вытеснят последних из процесса управления. Сфера применения HR-ботов стремительно расширяется, а их действия невидимы для пользователей, и в этом смысле боты являются «черными ящиками». Поэтому перед исследователями стоит задача тщательного рассмотрения структурного, функционального и этического аспектов действия данных автоматических агентов. При этом структурный аспект характеризует то, как работает бот - управляется он человеком или искусственным интеллектом. Функциональный аспект отражает задачи, которые призван решать бот. Этический аспект - это социально-культурные последствия применения ботов в управлении персоналом. Пока указанные аспекты исследованы недостаточно. Также практически неизученным остается вопрос о том, в какой мере боты используются для генерации аккаунтов сфабрикованных пользователей в социальных сетях с целью формирования позитивного имиджа компании и ее продвижения на рынке труда.

Ключевые слова: бот, HR-бот, чат-бот, управление человеческими ресурсами, HRфункция.

Статья подготовлена при финансовой поддержке РФФИ в рамках научного проекта «Структура бот-пространства онлайн социальных сетей: сетевой анализ» № 18-011-00988.

(C) Санкт-Петербургский государственный университет, 2019 
HR-боты в управлении человеческими ресурсами организации

\section{ВВЕДЕНИЕ}

В настоящее время широко обсуждается проблематика цифровизации экономики и общества, анализируются глобальные и локальные тренды в использовании цифровых технологий и цифровых решений компаниями и корпорациями [Цифровая экономика..., 2017]. Возрастает число публикаций по цифровизации HR-процессов, в которых рассматриваются опыт и перспективы внедрения цифровых технологий и решений в управление человеческими ресурсами [Берсин и др., 2017; Нагибина, Щукина, 2017; HR с цифровым лицом..., 2018; A New Age of Opportunities..., 2017]. Исследователи обращают внимание на переход к модели управления человеческими ресурсами на основе цифровых технологий, открывающих возможности использования больших данных для HR-аналитики и др. [Нагибина, Щукина, 2017; Bondarouk, Rue, 2009; Bondarouk, Brewster, 2016]. В отчете консалтинговой группы Deloitte «Международные тенденции в сфере управления персоналом» за 2017 г. фиксируется тенденция создания цифровых организаций, основанных на использовании искусственного интеллекта. При этом подчеркивается, что цифровые организации живут по новым правилам, которые связаны с переходом «от цифровизации HR-платформ к внедрению цифровых рабочих мест, цифровизации работы сотрудников, развертыванию технологий, которые меняют методы работы и взаимодействия между сотрудниками» [Берсин и др., 2017, с. 7]. В сборнике статей обращается внимание на тенденцию аугментации, т. е. сотрудничества человека и машины, в отличие от автоматизации, предполагающей вытеснение человека из производственного или управленческого процесса [HR с цифровым лицом..., 2018, с. 13]. В других исследованиях отмечается тенденция повышения роли искусственного интеллекта в принятии управленческих решений в HR-сфере (см., напр.: [A New Age of Opportunities..., 2017]).

B литературе по цифровизации HR-процессов часто упоминаются понятия «цифровые технологии», «цифровые инструменты», «цифровые решения», «цифровые сервисы», «чат-боты», при этом между ними нет четкого разграничения. Что подразумевается под использованием цифровых технологий? Что такое чат-боты - это цифровые технологии или цифровые инструменты? Чат-боты и HR-боты - это одно и то же или нет? Под цифровизацией в управлении человеческими ресурсами нередко понимается применение либо современных информационно-коммуникативных технологий (веб-технологий), либо искусственного интеллекта и роботов, либо цифровых платформ.

В настоящей статье не ставится задача подробного анализа названных выше понятий, хотя ее решение представляется весьма актуальным с точки зрения как теории управления человеческими ресурсами, так и управленческой практики. Целью данной статьи является определение понятия «НR-бот», его видов и функций в управлении человеческими ресурсами, а также вызовов, с которыми сталкиваются HR-подразделения в связи с внедрением в практику управления HRботов. 
Статья включает три части. В первой части анализируется понятие «бот», дается краткая характеристика видов и направлений использования ботов. Во второй - подробно рассмотрены HR-боты и их функции в управлении человеческими ресурсами. В третьей части на основе имеющихся исследований описаны возможности HR-ботов в повышении эффективности управления человеческими ресурсами, а также вызовы, с которыми сталкиваются HR-подразделения при внедрении HR-ботов. В заключении сделаны основные выводы и определены перспективы дальнейшего изучения HR-ботов.

\section{ПОНЯТИЕ «БОТ»: ТЕРМИНОЛОГИЧЕСКИЕ И СМЫСЛОВЫЕ АСПЕКТЫ}

Термин «бот» происходит от термина «робот». В большинстве исследований боты определяются как автоматизированные агенты, действующие на онлайнплатформах. Управляют данными агентами специально разработанные программы, которые формулируют решения и воздействуют на них без вмешательства человека. Автоматизированные агенты могут приспосабливаться к контексту, в котором они действуют [Gorwa, Guilbeault, 2018, p. 4].

Боты можно подразделить на два больших класса. Первый класс - это программы, образующие инфраструктуру поисковых систем, систем сканирования, индексирования и скремблирования (scraping). Они непосредственно не связаны с взаимодействием и поведением людей и представляют интерес скорее для специалистов по техническому обслуживанию Интернета и информационной безопасности [Gorwa, Guilbeault, 2018, p. 6].

Второй класс - это автоматизированные агенты, взаимодействующие в той или иной мере с человеком. К ним специалисты относят социальные боты, чатботы и спам-боты. Социальные боты - различного рода программы и программные устройства, работающие на платформах социальных сетей. С их помощью в социальных сетях генерируются аккаунты сфабрикованных пользователей, которые имитируют ряд функций участников социальной сети, включая рецензирование, слежение, распространение информации. Некоторые боты рассылают рекламную информацию, они также способны делать ссылки, в том числе вредоносные. Часто такие боты называют «сиблами» (sybil), подчеркивая их информационную опасность, а также то, что они управляют ложными узлами в социальной сети [Cao et al., 2012; Boshmaf et al., 2013; Mitter, Wagner, Strohmaier, 2014].

Чат-боты - специальные программы, взаимодействующие с человеком в режиме диалога и использующие для этого естественный язык. Они общаются с пользователями Интернета через конкретный интерфейс. Современные чат-боты - это довольно сложные программы, которые не только выполняют функцию диалога (например, отвечают на вопрос пользователя), но и решают более трудные задачи, помогая менеджерам по продажам общаться с клиентами компаний (например, Siri от Apple). Также они берут на себя функцию обмена сообщениями в социальных сетях Facebook: Messenger, Skype, Telegram и др. [Folstad, Brandtzaeg, 2017]. 
HR-боты в управлении человеческими ресурсами организации

Спам-боты - это сетевые устройства, которые используют вредоносные программы для распространения спама. Как правило, это не полностью автоматизированные системы, они управляются третьей стороной - в основном спамерами, т. е. людьми, которые применяют программные средства в своих целях [Gorwa, Guilbeault, 2018, p. 7]. Такие боты взламывают компьютеры, занимаются массовой рассылкой спама, в том числе в социальных сетях.

Некоторые специалисты относят к ботам марионеток, используемых для обмана аудитории (sockpuppet), и троллей. Однако это вряд ли справедливо, поскольку и те и другие - не автоматические программные системы как таковые, а физические лица, которые с помощью программных средств распространяют в Интернете ложь, сплетни, информацию, порочащую других людей. Они могут оказывать влияние на пользователей Сети для продвижения продуктов и информации в целях повышения или понижения репутации какого-то политического деятеля или бизнесмена.

Боты запрограммированы на внедрение, вмешательство как в саму информацию в Интернете, так и в способы ее передачи, причем их действия невидимы для пользователей, и в данном смысле они являются «черными ящиками». Это порождает настороженное отношение, тревогу и опасения в связи с их появлением в социальных сетях и на интернет-платформах [Murthy et al., 2016, p. 4955]. Поэтому при анализе ботов как автоматизированных агентов в сети Интернет важно учитывать три аспекта: 1) структурный; 2) функциональный; 3) этический [Gorwa, Guilbeault, 2018, p. 11-12]. Структурный аспект связан с тем, как работает агент (управляется человеком или искусственным интеллектом). Функциональный аспект подразумевает назначение бота, функции, которые он выполняет. Этический аспект обусловлен социально-культурными и социально-психологическими последствиями использования бота. В контексте настоящей статьи интерес представляют два последних аспекта.

Среди социальных ботов лучше других исследованы политические боты, которые получили широкое распространение в предвыборных кампаниях и масштабных политических акциях, таких как Brexit. В частности, в работе [Gallagher, 2015] выделяется пять направлений применения политических ботов: 1) хештегспам - прикрепление определенного хештега к нерелевантному контенту, что делает его непригодным для использования; 2) создание искусственных тенденций, которые затушевывают, нивелируют реальные тенденции и тем самым переключают внимание общественности и СМИ; 3) разворачивание кампаний по обвинению, разоблачению кандидата в ходе предвыборных выступлений и дебатов; 4) проведение кампании по реабилитации политика или чиновника, запятнавшего себя, например, участием в коррупционных действиях; 5) политическая пропаганда - продвижение по заказу идеологической, политической программы. Политические боты часто связаны с манипулированием общественным сознанием, поэтому к ним проявляется повышенный исследовательский интерес [Василькова, Легостаева, 2019]. Гораздо в меньшей степени изучены HR-боты, особенно 
этический аспект их применения. Научные публикации по обнаружению и соответствующему анализу этих ботов практически отсутствуют, хотя они так же, как и политические, могут быть связаны с манипулированием общественным сознанием.

Чат-боты широко используются организациями в интернет-коммуникации со своими целевыми аудиториями. Управляемые алгоритмами различной сложности, они реагируют на сообщения пользователей Сети, выбирая соответствующие выражения с помощью предварительно запрограммированных схем или алгоритмов машинного обучения. В устной коммуникации чат-бот может быть близок к ведению оживленного разговора с пользователем Сети, создавая иллюзию общения с другим человеком [Neff, Nagy, 2016, p. 4915]. Чат-боты нередко выступают как онлайн-помощники, советчики, гиды или партнеры по игре/развлечению. При этом их разработчики стремятся к максимальной имитации автоматизированными агентами реального поведения человека в коммуникативной ситуации, хотя это и не всегда удается. Не все пользователи Интернета приветствуют общение с чат-ботами, им не нравится разговаривать или переписываться с машиной.

Чат-боты применяются как в поисковых системах, так и на интернет-порталах, а также в социальных сетях. Они разрабатываются как по заказу организаций, так и самими пользователями для облегчения коммуникаций с различными организациями. В литературе, особенно научно-популярной, преобладает позитивная оценка чат-ботов с акцентом на их функционал как помощников в решении конкретных коммуникативных проблем. Однако не стоит забывать и о возможных негативных последствиях использования чат-ботов.

Авторы статьи [Neff, Nagy, 2016], рассматривая негативный опыт внедрения бота Tаy от Microsoft, сделали три важных вывода. Во-первых, интеллектуальные системы, вступающие во взаимодействие с пользователями Интернета, обладают уникальным статусом - будучи размещенными на различных интернет-платформах (в социальных сетях), они могут вести себя по-разному [Neff, Nagy, 2016, p. 4925]. Во-вторых, возможности ботов кроются в их взаимодействии с людьми в многообразных социальных контекстах. При этом следует иметь в виду, что чат-боты - это не просто механические устройства, которые обладают заданной и неизменной функциональностью. Компания Microsoft создавала Тау для игры молодых людей в Интернете. Но фактически бот использовался не так, как задумывали дизайнеры. Пользователи Twitter концептуализировали Тау как объективное представление о социальном мире, хотя дизайнеры не предполагали этого, что привело к негативным социальным последствиям. Бот повел себя непредсказуемым образом. Имитируя женский персонаж, Тау оскорбляла собеседников, высказывалась недопустимым образом по расовым и политическим вопросам, пользовалась ненормативной лексикой, что вызывало неподдельное возмущение пользователей, и Microsoft вынужден был закрыть аккаунт бота. Проблема заключалась в том, что алгоритм запоминания чат-бота оказался под влиянием ра- 
систской и сексистской риторики. В-третьих, когда люди общаются с ботами, их деятельность является симбиотической, что предполагает взаимную зависимость сторон, и этот аспект имеет принципиальное значение для оценки этической стороны внедрения ботов в повседневную жизнь [Neff, Nagy, 2016, p. 4926].

Таким образом, боты как автоматические агенты, действующие в интернетпространстве, не являются простыми механическими устройствами. Их присутствие свидетельствует о формировании новой реальности, в которой в социальные отношения встраиваются искусственные акторы, частично наделенные свойствами, присущими человеку. Поэтому анализ ботов, их действий в разных сферах общественной жизни представляется чрезвычайно актуальным.

В настоящее время боты активно внедряются в сферу управления человеческими ресурсами. Тема автоматизации и роботизации процессов управления человеческими ресурсами находится на пике популярности. Несмотря на это, в научной литературе отсутствует четкое определение HR-ботов, не раскрыты их специфика и влияние на эффективность управления персоналом.

\section{HR-БОТЫ: ФУНКЦИИ В УПРАВЛЕНИИ ЧЕЛОВЕЧЕСКИМИ РЕСУРСАМИ}

Понятие HR-бота чаще всего связывают с применением искусственного интеллекта в управлении человеческими ресурсами. HR-бот рассматривается как автоматический агент, используемый для повышения экономической эффективности HR-функции организации. B статье [AI and automation in HR...] HR-боты характеризуются как основанные на искусственном интеллекте программы для решения задач поиска, отбора, адаптации, коучинга персонала и повышения эффективности внутриорганизационных коммуникаций. По словам экспертов, искусственный интеллект способен собирать и обобщать демографические данные, историю работы с интервью кандидата и на этой основе предсказывать, насколько хорошо он сможет выполнять свою работу в компании, что позитивно влияет как на производительность HR-специалистов, так и на качество исполнения HRфункции организации [Берсин, 2019].

Достижения в области искусственного интеллекта позволяют внедрять в управление компьютерные технологии, которые способны решать задачи, присущие человеку и его познавательной деятельности [Tambe, Cappelli, Yakubovich, 2018 , p. 2]. Однако в отличие от других сфер менеджмента, например управления финансами, управление человеческими ресурсами представляет собой более сложный объект роботизации. Это обусловлено трудностями алгоритмизации поведения человека в организации, а также многозначностью критериев, используемых при принятии схожих управленческих решений в тех или иных социальных и культурных контекстах. Так, в различных организациях под ценными или талантливыми понимаются сотрудники с разными качествами, что не может не отразиться на алгоритмах поиска и отбора кандидатов на вакантную должность. Тем не менее по мере накопления и систематизации информации о практиках 
управления человеческими ресурсами возможности для внедрения HR-ботов расширяются.

В зависимости от способности искусственного интеллекта решать комплекс взаимосвязанных задач (сбор, обобщение, анализ данных, выработка управленческих решений) можно выделить HR-боты трех уровней сложности [Walker, 2018].

Первый уровень: HR-боты, основанные на специализированном искусственном интеллекте (artificial narrow intelligence), который имитирует речевые функции человека и применяет стандартизированные алгоритмы работы с информацией. Боты данного уровня - это специальные программы (машины), используемые для принятия решений на основе больших данных и статистически верифицированных алгоритмов. Примером являются чат-боты, которые способны распознавать паттерны голосовых команд и реагировать на них по заранее заданному сценарию. Чаще всего такие чат-боты применяются в массовом подборе, когда необходимо отвечать на стандартные вопросы или задавать стандартные вопросы кандидатам. По такому принципу работает бот Миа (Муа), который дает ответы на базовые вопросы об условиях труда: дате начала работы, предлагаемой заработной плате, процедуре оценки и т. п. Чат-боты рассматриваются как «персональные ассистенты» HR-специалиста, которые облегчают работу рекрутеров, повышают качество коммуникаций между работодателем и кандидатами.

Также существуют программы работы с естественным языком (Natural Language Processing), которые сканируют резюме кандидатов, чтобы заимствовать их словарный запас для написания текстов и общения с другими кандидатами. Они способны обращаться не только к языку кандидатов, но и к словарям, чтобы помочь, в частности, рекрутерам при написании объявления о работе. Кроме того, специальные программы (например, Jobscan Tutorial) помогают соискателям составлять и редактировать резюме, корректировать запрос о вакансии [How to Use Jobscan...]. Бот выявляет соответствие основных пунктов резюме требованиям компании и предлагает более подходящую вакансию, а также подсказывает, как откорректировать резюме, чтобы оно прошло первичный этап отбора. Некоторые специальные программы (например, Skillaz) осуществляют автоматический поиск кандидатов. Используя современные средства коммуникации (электронную почту, мессенджеры, социальные сети), они позволяют проводить скрининг резюме, предварительную оценку кандидатов на основе стандартизированных опросников, кейсов или даже игровых ситуаций, ранжировать кандидатов по заданному профилю, рассылать соискателям приглашения на интервью.

Специфика данных HR-ботов в том, что они предназначены для решения узкоспециализированных задач в управлении человеческими ресурсами, как правило, рутинных. Целесообразность их внедрения обусловлена необходимостью сокращения временных затрат на решение стандартных, повторяющихся задач управления человеческими ресурсами. Например, в рекрутменте они освобождают HRспециалистов от выполнения таких рутинных операций, как сбор и скрининг ре- 
зюме кандидатов, телефонные звонки соискателям, рассылка сообщений. На этом уровне аналитические функции человека практически не автоматизированы.

Второй уровень: HR-боты, основанные на искусственном интеллекте, предполагающем частичную автоматизацию аналитических функций человека (artificial general intelligence). Здесь речь идет о более сложных программах (машинах), охватывающих, как правило, не отдельные задачи, а совокупность задач в рамках конкретной HR-функции, или не одну, а несколько HR-функций (связанные в сеть программы - botnet). Так, применение бота HireVue при проведении видеоинтервью с кандидатами дает возможность создавать автоматически управляемый профиль кандидата и на этой основе формировать и обновлять базу кандидатов без участия рекрутера. Это происходит потому, что бот способен сохранять и анализировать большой объем слов и выражений, накапливаемых в ходе интервью. В качестве другого примера можно привести SAP SuccessFactors как систему связанных между собой программ, частично автоматизирующих процессы кадрового администрирования, подбора, адаптации, оценки, вознаграждения, обучения и развития персонала. Используя SuccessFactors, HR-специалисты могут проводить онлайн-анализ HR-метрик, заложенных в систему. Эта программа имеет ряд мобильных приложений, которыми рядовые сотрудники могут пользоваться для доступа к необходимым для них данным.

Особенности указанных HR-ботов заключаются в том, что с использованием более сложных программ, основанных на искусственном интеллекте, снимается часть проблем первого уровня, например связанных с формированием и постоянным обновлением базы кандидатов. Кроме того, машины этого уровня лучше имитируют поведение человека: их речевой репертуар шире, чем у машин первого уровня, в результате чего их общение с человеком становится более продуктивным. Данные программы часто связаны в единую сеть. В то же время боты не могут заменить человека, если речь идет, например, о привлечении талантов в компанию. Для коммуникации с талантливым кандидатом нужны нестандартизированные подходы к поиску и подбору, которые машина этого уровня обеспечить не в состоянии.

B целом HR-боты второго уровня создают возможности для перехода от функциональной модели управления человеческими ресурсами к процессной, основанной на интеграции HR-процессов с бизнес-процессами [Sheth, 2018; Guha, 2019]. Однако, по меткому замечанию Дж. Берсина, они являются инструментом для улучшений, а не для самостоятельного принятия решений [Берсин, 2019].

Третий уровень: HR-боты, основанные на суперискусственном интеллекте (artificial super intelligence), т.е. на самообучающихся программах (машинах), имитирующих поведение человека. Они в состоянии конкурировать с человеком или даже заменить его при выполнении, например, аналитических операций. Эксперты Deloitte выделяют специальные программы со встроенной когнитивной функцией, которые являются инструментами предикативной аналитики больших данных. Эти программы способны предвидеть, как личностные и поведенче- 
ские характеристики реальных или потенциальных сотрудников могут повлиять на эффективность работы компании, анализировать социальную активность потенциальных кандидатов, активность друзей в социальных сетях, выявлять тех из них, кому компания может направить предложение о работе, определять эмоциональное состояние пользователей сетей и др. [Подбор персонала в цифровую эпоху, 2018]. Однако, по оценке специалистов, данный уровень еще не столь актуален для HR-подразделений, в том числе в связи со сложностями самого объекта роботизации [Tambe, Cappelli, Yakubovich, 2018; Walker, 2018].

Таким образом, HR-боты - это автоматические агенты, основанные на применении искусственного интеллекта и предназначенные для оптимизации, повышения эффективности работы HR-специалистов и в целом HR-подразделений.

B зависимости от того, какой объем функций управления человеческими ресурсами способен взять на себя искусственный интеллект, HR-боты подразделяются на три вида (табл. 1): 1) поисковый; 2) коммуникативный (использование как письменной, так и устной коммуникации); 3 ) синтетический (совмещение нескольких программ - ботнеты).

Таблица 1. Виды HR-ботов в практике управления человеческими ресурсами

\begin{tabular}{|c|c|c|c|}
\hline Вид HR-бота & Пример & Функционал & Компания \\
\hline 1 & 2 & 3 & 4 \\
\hline \multirow{3}{*}{ Поисковый } & Skillaz & $\begin{array}{l}\text { Массовый рекрутмент } \\
\text { (подбор): поиск резюме на } \\
\text { работных сайтах; онлайн- } \\
\text { анкетирование кандидатов } \\
\text { с последующим } \\
\text { ранжированием; рассылка } \\
\text { СМС } \\
\text { с приглашением на } \\
\text { интервью }\end{array}$ & $\begin{array}{l}\text { ПАО «Вымпелком», } \\
\text { ПАО «Банк “ФК } \\
\text { Открытие"», } \\
\text { ПАО «Газпром нефть», } \\
\text { «Азбука вкуса», } \\
\text { ПАО «Почта-банк», } \\
\text { AO «Альфа-Банк», } \\
\text { Uber и др. }\end{array}$ \\
\hline & Job Pal & $\begin{array}{l}\text { Рекрутмент: поиск } \\
\text { и скрининг резюме } \\
\text { кандидатов через } \\
\text { мессенджер Twitter }\end{array}$ & $\begin{array}{l}\text { AIRBUS, } \\
\text { StepStone, } \\
\text { TALENTSOFT и др. }\end{array}$ \\
\hline & $\begin{array}{l}\text { TARA } \\
\text { Yodas }\end{array}$ & $\begin{array}{l}\text { Рекрутмент: поиск и } \\
\text { скрининг резюме ИТ- } \\
\text { специалистов } \\
\text { в соцсетях, на работных } \\
\text { сайтах, на площадке } \\
\text { GitHub }\end{array}$ & $\begin{array}{l}\text { CISCO, } \\
\text { GSVlabs, } \\
\text { SubwayTalent и др. }\end{array}$ \\
\hline
\end{tabular}


Окончание табл. 1

\begin{tabular}{|c|c|c|c|}
\hline 1 & 2 & 3 & 4 \\
\hline \multirow{2}{*}{ Коммуникативный } & VCV & $\begin{array}{l}\text { Рекрутмент (отбор): } \\
\text { рассылка кандидатам } \\
\text { приглашений на интервью; } \\
\text { видеозапись интервью } \\
\text { с кандидатом по заранее } \\
\text { составленным рекрутерами } \\
\text { вопросам }\end{array}$ & $\begin{array}{l}\text { Mars, } \\
\text { «Балтика», } \\
\text { «Билайн», } \\
\text { ПАО «Ростелеком» } \\
\text { и др. }\end{array}$ \\
\hline & Мия & $\begin{array}{l}\text { Рекрутмент (подбор, } \\
\text { отбор): ответы на типовые } \\
\text { вопросы соискателей; } \\
\text { оценка соискателей } \\
\text { с последующим } \\
\text { рейтингованием }\end{array}$ & $\begin{array}{l}\text { L'Oréal, } \\
\text { PepsiCo, } \\
\text { Adecco, } \\
\text { Advantage Solutions } \\
\text { и др. }\end{array}$ \\
\hline Синтетический & Робот Вера & $\begin{array}{l}\text { Рекрутмент (подбор, } \\
\text { отбор): подбор резюме под } \\
\text { вакансию } \\
\text { на работных сайтах; } \\
\text { удаление дублей } \\
\text { резюме; телефонные } \\
\text { звонки кандидатам; } \\
\text { предоставление } \\
\text { соискателям информации } \\
\text { о компании; видео- } \\
\text { интервью } \\
\text { с кандидатами }\end{array}$ & $\begin{array}{l}\text { ПАО «МТС», } \\
\text { X5 Retail Group } \\
\text { («Пятерочка»), } \\
\text { ООО «Кока-Кола } \\
\text { ЭйчБиСи Евразия», } \\
\text { «Дикси» и др. }\end{array}$ \\
\hline
\end{tabular}

С о с т а в ле н о п о: [Робот подобрал персонал..., 2017; Сирвида-Льорентэ, 2018].

Как видно из табл. 1, наиболее широко HR-боты применяются в рекрутменте персонала. Согласно результатам исследования HeadHunter, в 2018 г. 16\% компаний в качестве приоритетной задачи ставили внедрение новых автоматизированных решений и ИТ-разработок (боты, приложения, HRIS и ATS системы ${ }^{1}$ ) [Игнатова, 2019, с. 25]. При этом среди задач, которые решает искусственный интеллект в управлении человеческими ресурсами, на первое место, по мнению экспертов, выходят первичный скрининг и ранжирование резюме кандидатов. Управление брендом через мобильные приложения и социальные сети; автоматизация коммуникационных задач для организационных запросов, формирование программ

${ }^{1}$ HRIS - информационная система поддержки управления человеческими ресурсами (Human Resources Information System); ATS - автоматизированная система управления кандидатами (Applicant Tracking System). 
обучения под индивидуальный профиль сотрудников, автоматизация коммуникационных задач для адаптации, прогнозирование успеха кандидата на заданных ролях занимают соответственно 6-10-е места [Игнатова, 2019, с. 62]. Искусственный интеллект в управлении человеческими ресурсами задействован прежде всего при поиске кандидатов (63\% ответов); в обучении сотрудников, но здесь ему отводится менее значимая роль (47\%); в их адаптации его значение еще ниже (36\% ответов) [Игнатова, 2019, с. 63].

По оценке экспертов Deloitte, одна из ключевых тенденций развития рынка цифровых HR-решений - предложение разных модификаций роботов-рекрутеров, способных частично или полностью заменить HR-специалистов при подборе персонала. Эксперты считают, что робот-рекрутер сокращает временные и трудовые затраты на подбор персонала как минимум в 10 раз, что не может не привлекать внимание компаний к данному цифровому решению. Еще одна тенденция, на которую обращается внимание, - это рост предложения чат-ботов, используемых в рекрутменте. По мнению экспертов, чат-боты предоставляют компаниям широкие возможности оптимизации административной работы в процессе рекрутмента (планирование встреч, формирование профилей кандидатов, ведение базы соискателей), повышения эффективности коммуникаций с соискателями (общение в режиме 24/7, использование приложений для работы чат-ботов в мессенджерах и др.) [Подбор персонала в цифровую эпоху, 2018].

Вместе с тем в настоящее время возможности чат-ботов выходят за рамки рекрутмента. Они рассматриваются как универсальные помощники HRспециалистов, используемые на всех этапах управления персоналом, начиная с поиска и заканчивая планированием карьеры сотрудника. Как отмечает Б. Шет, преимущество современных чат-ботов состоит в том, что они позволяют HRкомандам проводить в режиме онлайн оценку навыков и результативности работы сотрудников, опросы об удовлетворенности работой, взаимодействовать с каждым из них на индивидуальной основе в соответствии с личной ситуацией. С их помощью можно выявлять интересы и цели сотрудников, актуальные проблемы, в том числе эмоционального плана, а также определять пики и спады трудовой активности. Такая информация полезна для оптимизации календарных графиков работы персонала, эффективного распределения задач, планирования обучения и развития сотрудников и т. п. [Sheth, 2018, p. 162-163].

По мнению ряда экспертов, внедрение чат-ботов способствует формированию бренда работодателя, привлекательного для талантливых, высокорезультативных кандидатов и сотрудников. Как отмечает Н. Яни, чат-боты - это умные ассистенты, которые облегчают труд HR-специалистов, помогают им в решении текущих задач, высвобождая время для выполнения стратегических функций [Jani, 2018]. Для молодого поколения сотрудников работодатель, использующий современные цифровые технологии и цифровые инструменты, более привлекателен, поскольку мир молодого человека глубоко погружен в интернет-среду. Яни связывает будущее управление человеческими ресурсами с передачей чат-ботам 
функции коммуникации HR-специалистов с потенциальными и реальными сотрудниками, что может резко повысить эффективность HR-функции и существенно улучшит имидж компании на рынке труда.

В целом среди экспертов, в той или иной мере связанных с цифровизацией HR-функции, преобладает переоценка функциональных аспектов HR-ботов (см., напр.: [Салливан, 2016; Jani, 2018; Sheth, 2018]). В связи с этим важно выяснить: каковы реальные возможности HR-ботов в повышении эффективности HRфункции; могут ли они заменить HR-специалистов и с какими вызовами сталкиваются HR-подразделения при внедрении ботов.

\section{HR-БОТЫ: ВЛИЯНИЕ НА ЭФФЕКТИВНОСТЬ НR-ФУНКЦИИ}

Опираясь на мнения практикующих специалистов в области управления человеческими ресурсами (HR-менеджеров, консультантов, разработчиков цифровых HR-решений), выделим сильные и слабые стороны современных HR-ботов (табл. 2) и, исходя из этого, оценим их потенциал повышения эффективности HRфункции организации.

Как следует из табл. 2, применение HR-ботов способствует росту производительности труда рекрутеров за счет расширения отборочной воронки и сокращения времени обработки одной вакансии. Их наличие дает возможность HR-подразделениям выполнять больший объем работы, используя меньший штат сотрудников. В этом случае экономятся финансовые ресурсы, выделяемые на оплату труда. Также HR-боты сокращают непроизводительные расходы времени персонала за счет оптимизации внутриорганизационных коммуникаций. Кроме того, они повышают оперативность коммуникаций работодателя с кандидатами, что позитивно влияет на имидж организации на рынке труда. HRботам передаются рутинные операции, вследствие чего высвобождается время HR-подразделения на решение стратегических, творческих задач. Все это, на наш взгляд, способствует росту удовлетворенности HR-специалистов работой в компании.

B то же время возможности современных HR-ботов ограничены прежде всего тем, что они не способны заменить собой сотрудника, а играют роль помощника и зависимы от квалификации команды, которая их создает и обслуживает. Ожидания того, что боты смогут устранить субъективный фактор при отборе персонала и преградить вхождение в компанию несоответствующих кандидатов, завышены. Со временем люди научатся «проходить» HR-боты, манипулировать ими, как это случилось с ботом Тау. Кроме того, мнение о том, что боты, в отличие от людей, не допускают ошибок, вряд ли справедливо. С помощью бота можно выбрать человека, подходящего по квалификационным параметрам, но «не вписывающегося» в организационную культуру. И неизвестно, что хуже для компании: недостаток квалификации или качества сотрудника, разрушающие ценности организационной культуры. 
В. Н. Минина

Таблица 2. Сферы применения HR-ботов: сильные и слабые стороны

\begin{tabular}{|c|c|c|}
\hline $\begin{array}{c}\text { Сферы применения } \\
\text { HR-ботов }\end{array}$ & Сильные стороны & Слабые стороны \\
\hline 1 & 2 & 3 \\
\hline $\begin{array}{l}\text { Рекрутмент, } \\
\text { чаще всего массовый } \\
\text { подбор }\end{array}$ & $\begin{array}{l}\text { - Работа } 24 \text { часа в сутки, } \\
365 \text { дней в году и без } \\
\text { заработной платы } \\
\text { - Способность отвечать на } \\
\text { тысячи диалоговых вопросов } \\
\text { в неделю } \\
\text { - } \text { Автоматический поиск } \\
\text { кандидатов по различным } \\
\text { базам данных } \\
\text { - Проведение в онлайн- } \\
\text { режиме различных видов } \\
\text { тестирования и первичной } \\
\text { проверки профессиональных } \\
\text { параметров кандидатов } \\
\text { - Ранжирование резюме } \\
\text { кандидатов по формальным } \\
\text { признакам } \\
\text { - странение механических } \\
\text { ошибок в работе с } \\
\text { информацией о кандидате, } \\
\text { которые допускают } \\
\text { рекрутеры } \\
\text { - Снижение влияния } \\
\text { субъективных факторов, } \\
\text { определяющих состояние } \\
\text { обоих участников } \\
\text { собеседования (усталость, } \\
\text { раздражительность, потеря } \\
\text { мотивации) } \\
\text { - Автоматизация рутинных } \\
\text { операций, в том числе } \\
\text { кадрового делопроизводства }\end{array}$ & 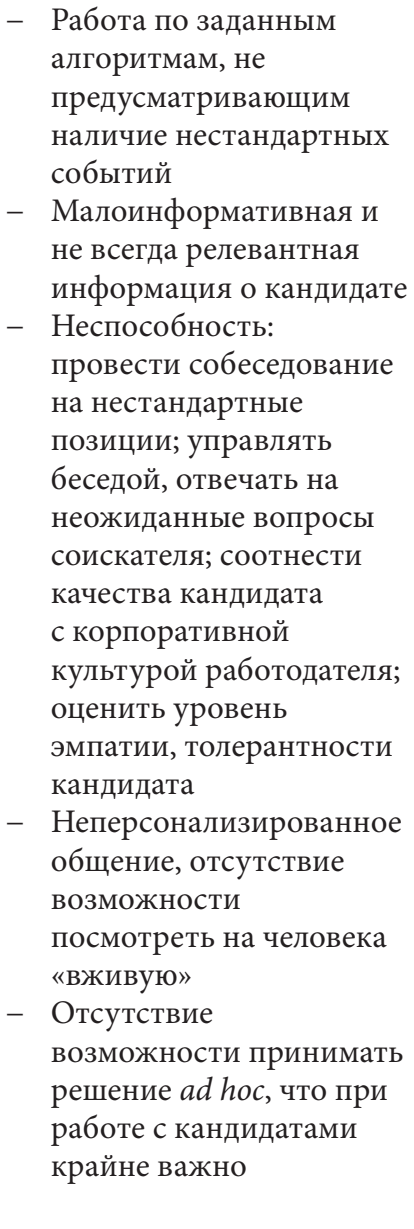 \\
\hline $\begin{array}{l}\text { Формирование } \\
\text { позитивного имиджа } \\
\text { работодателя/бренда } \\
\text { работодателя }\end{array}$ & $\begin{array}{l}\text { - Позитивная оценка } \\
\text { молодежной аудиторией } \\
\text { возможности «общения» с } \\
\text { ботом } \\
\text { - } \text { Позиционирование } \\
\text { технологичности и } \\
\text { инновационности компании, } \\
\text { что важно для продвижения } \\
\text { компании }\end{array}$ & $\begin{array}{l}\text { - Работа по заданным } \\
\text { алгоритмам }\end{array}$ \\
\hline
\end{tabular}


Окончание табл. 2

\begin{tabular}{|c|c|c|}
\hline 1 & 2 & 3 \\
\hline $\begin{array}{l}\text { Управление } \\
\text { внутриорганизационными } \\
\text { коммуникациями }\end{array}$ & $\begin{aligned} & \text { - } \text { Автоматическое } \\
& \text { обслуживание сотрудников: } \\
& \text { смена адреса или начисление } \\
& \text { бонусов, рекомендации по } \\
& \text { выбору программы обучения } \\
& \text { и др. } \\
& \text { - Ответы на часто } \\
& \text { возникающие у сотрудников } \\
& \text { вопросы }\end{aligned}$ & $\begin{array}{l}\text { - Манипуляция } \\
\text { чат-ботами } \\
\text { со стороны } \\
\text { пользователей }\end{array}$ \\
\hline Адаптация персонала & $\begin{array}{ll}\text { - } & \text { Проверка персональной } \\
& \text { информации о вновь } \\
& \text { прибывших сотрудниках } \\
- & \text { Консультирование новичков } \\
\text { по разным вопросам } \\
\text { в течение всего периода } \\
\text { адаптации } \\
\text { - } \text { Решение важных проблем } \\
\text { новых сотрудников: } \\
\text { предоставление } \\
\text { банковских данных } \\
\text { для расчета заработной } \\
\text { платы, выбор } \\
\text { дополнительных льгот, } \\
\text { планирование обучения на } \\
\text { рабочем месте, } \\
\text { а также медицинское } \\
\text { тестирование } \\
\text { в случае необходимости }\end{array}$ & $\begin{array}{l}\text { - Работа по заданным } \\
\text { алгоритмам }\end{array}$ \\
\hline
\end{tabular}

С ост а влен о по: [Салливан, 2016; Гринштейн, 2017; Стаценко, 2017; Burlacu, 2018; Is technology taking the $\mathrm{H}$ out of HR...].

Практики не ожидают от HR-ботов прорывных решений и рассматривают их как полезный инструмент оптимизации HR-функции, но при условии, что и HRспециалисты, и компания в целом относятся к ботам не как к «модной фишке», a как к инструменту повышения эффективности труда.

Какие риски возникают для HR-подразделений в связи с внедрением HRботов? Как свидетельствуют результаты исследования HeadHunter, существуют следующие риски:

- снижение качества управленческих решений, связанных с персоналом, поскольку они будут приниматься без учета человеческого фактора и эмоционального интеллекта; 
- накопление ошибок при принятии управленческих решений, поскольку трудно разобраться, как и где ошибся бот и на основе чего ошибки возникли;

- значительное усложнение входа в HR-профессию из-за того, что HRспециалисты должны будут обладать компетенциями, отличными от тех, которые имеются у них сейчас [Игнатова, 2019, с. 66].

Действительно, внедрение HR-ботов потребует от HR-специалистов владения такими компетенциями, как: работа в межфункциональной проектной команде (прежде всего с ИТ-специалистами); аналитические навыки (определение HR-метрик, работа с большими данными); цифровые компетенции (работа с облачными решениями и технологиями, цифровыми инструментами).

Помимо этого, риски связаны с высокими темпами развития рынка цифровых HR-инструментов, на котором присутствуют разные игроки, предлагающие широкий спектр цифровых продуктов и услуг. При этом не все продукты одинаково пригодны и эффективны для конкретного бизнеса. Ошибки выбора могут негативно сказаться на работе HR-подразделения, поэтому, прежде чем внедрять HR-боты, необходимо ответить на ключевые вопросы: какова цель использования бота; что ожидает от него бизнес; как бот встраивается в общую систему управления компанией; в какой мере сотрудники HR-подразделения готовы к работе с ботом; какие компетенции они должны приобрести или развить? Ответы на них помогут сделать процесс внедрения HR-ботов более «мягким» и продуктивным.

\section{ЗАКЛЮЧЕНИЕ}

Резюмируя, необходимо подчеркнуть, что на рынке предлагаются боты с различным уровнем искусственного интеллекта, ориентированные на решение разных задач. Чем сложнее бот, тем выше требования к его пользователям, к организации рабочих процессов. При работе с HR-ботами важно иметь в виду, что взаимодействие человека с ними представляет собой симбиотическую систему, в которой стороны взаимосвязаны и взаимозависимы. Распределение функций между человеком и роботом порождает класс проблем, требующих как научного осмысления, так и практического решения. По мнению исследователей, к числу таких проблем относятся снижение осведомленности руководителей и специалистов о рабочей ситуации, а также бдительности и уровня контроля процессов. Кроме того, организационные проблемы создает злоупотребление возможностями искусственного интеллекта. Как следствие, возникает недоверие к роботам и их неприятие [Cascio, Montealegre, 2016, p. 358].

Недостаточно изученными являются социально-психологические и этические аспекты взаимодействия человека и робота. Возникают вопросы: какие психологические проблемы порождает зависимость человека от самообучающейся машины; насколько оправдана с этической точки зрения замена человеческого общения взаимодействием человека с машиной в процессе подбора и отбора 
персонала, а также социальной адаптации; почему одни группы сотрудников реагируют на внедрение роботов позитивно, а другие негативно? Эти и другие вопросы могут стать отправной точкой исследований практики применения HRботов.

Опыт показывает, что область использования HR-ботов расширяется. Bсе чаще их применяют для формирования позитивного имиджа компании через социальные медиа (социальные сети). В связи с этим важно выяснить, как работают боты в социальных сетях, являются ли они аккаунтами сфабрикованных пользователей с целью манипулирования общественным сознанием. Пока этот вопрос практически не изучен. Все это также открывает широкие горизонты для научных исследований практики применения HR-ботов.

\section{Литература на русском языке}

Берсин Дж., Пелстер Б., Шварц Дж., Ван дер Вивер Б. 2017. Новые правила игры в циифровую эпоху: исследование "Делойта» «Международные тендениии в сфере управления персоналом» за 2017 год. URL: https://www2.deloitte.com/content/dam/Deloitte/ru/Documents/ human-capital/russian/hc-2017-global-human-capital-trends-gx-ru.pdf (дата обращения: 19.04.2019).

Берсин Дж. 2019. Искусственный интеллект в HR. Talent management. URL: https://www.talentmanagement.com.ua/5202-iskusstvennyj-intellekt-v-hr (дата обращения: 17.04.2019).

Василькова В. В., Легостаева Н. И. 2019. Социальные боты в политической коммуникации. Вестник Российского университета дружбы народов. Серия: Соииология 19 (1): 121-133.

Гринштейн С. 2017. Перспективы HR-роботов в области подбора персонала - текущие реалии, мнения и опыт экспертов. Habr. URL: https:/habr.com/ru/post/321070/ (дата обращения: 04.06.2019).

Игнатова М. 2019. На что обращать внимание НR-специалисту? Ключевые иифры и тренды рынка труда. URL: https://hhcdn.ru/file/16757261.pdf (дата обращения: 15.06.2019).

Нагибина Н. И., Щукина А. А. 2017. HR-Digital: цифровые технологии в управлении человеческими ресурсами. Интернет-журнал «Науковедение» 9 (1). URL: http://naukovedenie.ru/ PDF/24EVN117.pdf. (дата обращения: 17.04.2019).

Подбор персонала в цифровую эпоху. 2018. Deloitte. URL: https://www2.deloitte.com/by/ru/pages/ human-capital/articles/2018/podbor-personala-v-cifrovuyu-ehpohu.html (дата обращения: 06.05.2019).

Робот подобрал персонал для банка «Открытие». 2017. URL: https://therunet.com/news/26631 (дата обращения: 06.05.2019).

Салливан Дж. 2016. Чат-боты в подборе персонала. HR-Portal. URL: http://hr-portal.ru/article/ chat-boty-v-podbore-personala (дата обращения: 29.04.2019).

Сирвида-Льорентэ С. 2018. Как живет рынок HR-ботов: поле деятельности для программиста. Geekbrains. URL: https://geekbrains.ru/posts/hr_bots (дата обращения: 06.05.2019).

Стаценко H. 2017. Могут ли боты заменить HR-специалистов? Мнения экспертов. Rusbase. URL: https://rb.ru/opinion/hr-bots/ (дата обращения: 06.05.2019).

Цифровая экономика: глобальные тренды и практика российского бизнеса. 2017. Доклад. М.: НИУ «Высшая школа экономики». URL: https://imi.hse.ru/pr2017_1 (дата обращения: 29.04.2019).

HR с цифровым лицом: как построить организацию будущего. Сборник статей. 2018. Harvard Business Review - Россия. URL: http://www.interface.ru/iarticle/files/39884_49142845.pdf (дата обращения: 29.04.2019). 


\section{References in Latin Alphabet}

AI and automation in HR: Impact, adoption and future workforce. Digital HR Tech. URL: https://www. digitalhrtech.com/ai-in-hr-impact-adoption-automation/ (accessed: 15.05.2019).

A New Age of Opportunities. What Does Artificial Intelligence Mean for HR Professionals? URL: https://www.hrpa.ca/Documents/Public/Thought-Leadership/HRPA-Report-Artificial-Intelligence-20171031.PDF (accessed: 15.05.2019).

Bondarouk T. V., Rue H. J. M. 2009. Electronic human resource management: Challenges in the digital era. The International Journal of Human Resource Management 20 (3): 505-514.

Bondarouk T., Brewster. Chr. 2016. Conceptualising the future of HRM and technology research. International Journal of Human Resource Management 27 (21): 2652-2671.

Boshmaf Y., Muslukhov I., Beznosov K., Ripeanu M. 2013. Design and analysis of a social botnet. Computer Networks 57 (2): 556-578.

Burlacu G. 2018. What EY learned when it started using HR bots. TLNT: Talent Management \& HR. URL: https://www.tlnt.com/what-ey-learned-when-it-started-using-hr-bots/ (accessed: 11.06.2019).

Cao Q., Sirivianos M., Yang X., Pregueiro T. 2012. Aiding the detection of fake accounts in large scale social online services. USENIX Association. URL: https://www.usenix.org/system/files/conference/nsdi12/nsdi12-final42_2.pdf (accessed: 07.02.2019).

Cascio W. F., Montealegre R. 2016. How technology is changing work and organizations. The Annual Review of Organizational Psychology and Organizational Behavior 3: 349-375.

Folstad A., Brandtzaeg P. B. 2017. Chatbots and the new world of HCI. Interactions 24 (4): 38-42.

Gallagher E. 2015. Mexican botnet dirty wars. Presented at the Chaos Communication Camp. Zehdenick, Germany. URL: https://events.ccc.de/camp/2015/Fahrplan/events/6795.html (accessed: 07.02.2019).

Gorwa R., Guilbeault D. 2018. Understanding bots for policy and research: Challenges, methods, and solutions. URL: http://arxiv.org/abs/1801.06863v1.pdf (accessed: 07.02.2019).

Guha A. 2019. Why human HR should not fear AI-powered bots. People Matters. URL: https://www. peoplemattersglobal.com/article/future-jobs/algorithms-to-screen-in-not-screen-out-candidates-x0pa-founder-21239 (accessed: 07.02.2019).

How to use Jobscan: A step-by-step guide. Jobscan. URL: https://www.jobscan.co/jobscan-tutorial (accessed: 04.06.2019).

Is technology taking the $\mathrm{H}$ out of HR? Chatbots VS humans. CakeHR. URL: https://blog.cake.hr/chatbots-in-hr-technology-human-resources/ (accessed: 04.06.2019).

Jani N. 2018. How HR chatbots are creating the employer brand for an enterprise? URL: https:// chatbotsjournal.com/how-hr-chatbots-are-creating-the-employer-brand-for-an-enterprise4a3ac1191335 (accessed: 11.06.2019).

Mitter S., Wagner C., Strohmaier M. 2014. Understanding the impact of socialbot attacks in online social networks. URL: http://arxivpreprintarXiv:1402.6289.pdf (accessed: 20.03.2019).

Murthy D., Powell A. B., Tinati R., Anstead N., Carr L., Halford S. J., Weal M. 2016. Bots and political influence: A sociotechnical investigation of social network capital. International Journal of Communication 10: 4952-4971.

Neff G., Nagy P. 2016. Talking to bots: Symbiotic agency and the case of Tay. International Journal of Communication 10: 4915-4931.

Sheth B. 2018. Chat bots are the new HR managers. Strategic HR Review 17 (3): 162-163.

Tambe P., Cappelli P., Yakubovich V. 2018. Artificial intelligence in human resources management: Challenges and a path forward. SSRN Electronic Journal (January): 1-34. URL: https://papers. ssrn.com/sol3/papers.cfm?abstract_id=3263878 (accessed: 30.08 .2019 ).

Walker J. 2018. Artificial intelligence in HR - FAQs you need to be able to answer. myHRfuture. URL: https://www.myhrfuture.com/blog/2018/6/22/artificial-intelligence-in-hr-faqs-you-need-to-beable-to-answer (accessed: 17.05.2019). 


\section{Russian Language References Translated into English}

Bersin J., Pelster B., Shvarts J., Van der Viver B. 2017. Deloitte’s study “International trends in personnel management” for 2017. URL: https://www2.deloitte.com/content/dam/Deloitte/ru/Documents/ human-capital/russian/hc-2017-global-human-capital-trends-gx-ru.pdf (accessed: 19.04.2019). (In Russian)

Bersin J. 2019. Artificial Intelligence in HR. Talent management. URL: https://www.talent-management. com.ua/5202-iskusstvennyj-intellekt-v-hr (accessed: 17.04.2019). (In Russian)

Vasilkova V. V., Legostaeva N. I. 2019. Social bots in political communication. Vestnik Rossiiskogo universiteta druzhby narodov. Seriia: Sotsiologiia 19 (1): 121-133. (In Russian)

Grinshtein S. 2017. Perspectives of HR robots in the field of recruitment - current realities, opinions and experience of experts. Habr. URL: https://habr.com/ru/post/321070/ (accessed: 04.06.2019). (In Russian)

Ignatova M. 2019. What should HR specialist pay attention to? Key numbers and trends in the labor market. URL: https://hhcdn.ru/file/16757261.pdf (accessed: 15.06.2019). (In Russian)

Nagibina N. I., Shhukina A. A. 2017. HR digital: Digital technologies in Human Resource Management. Internetzhurnal «Naukovedenie»9 (1). URL: http://naukovedenie.ru/PDF/24EVN117.pdf. (accessed: 17.04.2019). (In Russian)

Recruitment in the digital age. 2018. Deloitte. URL: https:/www2.deloitte.com/by/ru/pages/human-capital/articles/2018/podbor-personala-v-cifrovuyuehpohu.html (accessed: 06.05.2019). (In Russian)

The robot recruited staff for the bank "Otkrytie". URL: https://therunet.com/news/26631 (accessed: 06.05.2019). (In Russian)

Sullivan J. 2016. Chat bots in recruitment. HR-Portal. URL: http://hr-portal.ru/article/chat-boty-vpodbore-personala (accessed: 29.04.2019). (In Russian)

Sirvida-Lorente S. 2018. How the HR bots market lives. Geekbrains. URL: https:/geekbrains.ru/posts/ hr_bots (accessed: 06.05.2019). (In Russian)

Stacenko N. 2017. Can bots replace HR specialists? Expert opinions. Rusbase. URL: https://rb.ru/ opinion/hr-bots/ (accessed: 06.05.2019). (In Russian)

Digital Economy: Global Trends and Russian Business Practice. Report. 2017. Moscow: NIU "Vysshaia shkola ekonomiki”. URL: https://imi.hse.ru/pr2017_1 (accessed: 29.04.2019). (In Russian)

HR with a digital face: how to build an organization of the future: Collection of articles. 2018. Harvard Business Review - Rossiia. URL: http://www.interface.ru/iarticle/files/39884_49142845.pdf (accessed: 29.04.2019). (In Russian)

Статья поступила в редакцию 2 августа 2019 г.

Контактная информация

Статья рекомендована в печать 11 сентября 2019 г.

Минина Вера Николаевна - д-р соц. наук, проф.; vminina@spbu.ru

\section{HR BOTS IN HUMAN RESOURCE MANAGEMENT OF AN ORGANIZATION}

\section{N. Minina}

St. Petersburg State University, 7-9, Universitetskaya nab., St. Petersburg, 199034, Russian Federation

For citation: Minina V.N. 2019. HR bots in human resource management of an organization. Vestnik of Saint Petersburg University. Management 18 (3): 400-418. https://doi.org/10.21638/11701/spbu08.2019.304

The article is written in framework of the project "The structure of the botnet space of social networks: network analysis" supported by the Russian Foundation for Basic Research. Project No. 18-011-00988. 
The article analyzes a relatively new phenomenon of the digital economy - HR bots. The author outlines that in scientific literature there is no clear definition what HR bots are, what are their specific features are, and what their impact on the effectiveness of human resource management is. The objectives of the article are to define the concept of an "HR bot", identify its types and functions in the human resource management, and consider the challenges that HR departments face regarding the implementation of HR bots. The article consists of three sections. In the first section the author discusses a more general concept of a "bot", describes the type and directions of using bots. The second section relates to a detailed consideration of HR bots, their types and functions in human resource management. In the third section basing on the research available in the field and experts' opinion the author characterizes HR bots' capabilities in improving the efficiency of human resource management and the challenges that HR departments face when implementing HR bots. The key findings of the article are: the concept of an HR bot is clarified; the typology of HR bots is carried out; the scope of HR bot application is systematized, as well as their strengths and weaknesses, and prospects for further research in the field are identified. The article systematizes the diverse knowledge on bots and HR bots, therefore it can be useful both to researchers and practitioners in the field of human resource management.

Keywords: bot, HR bot, chat bot, human resource management, HR function.

Received: August 2, 2019

Accepted: September 11, 2019

Contact information

Vera N. Minina - Dr. Sci. in Sociology, Professor; vminina@spbu.ru 